\title{
MELHORAMENTO DO CAFEEIRO: XLI. PRODUTIVIDADE DO HÍBRIDO DE TIMOR, DE SEUS DERIVADOS E DE OUTRAS FONTES DE RESISTÊNCIA A HEMILEIA VASTATRIX ( $\left.{ }^{1}\right)$
}

\author{
ALCIDES CARVALHO $(2,3)$, LUIZ CARLOS FAZUOLI $(2,3)$ \\ O WALDIR MARQUES DA COSTA $(2,3)$
}

\begin{abstract}
RESUMO
Progênies do café Hibrido de Timor e $\mathrm{F}_{2}-\mathrm{F}_{4}$ oriundas de cruzamentos desse café com outros cultivares resistentes ou não a Hemileia vastatrix e cruzamentos entre outras fontes de resistência ao patógeno, foram avaliadas em três experimentos, em Campinas, para observação de sua produtividade, em relação a alguns cultivares de Coffea arabica tomados como testemunhas. As progênies do Hibrido de Timor apresentaram pequena produtividade, indicando baixa adaptação, com exceção daquelas de prefixos C 1737, C 1738 e C 1699. As progênies derivadas de cruzamentos do Hibrido de Timor com cultivares de porte pequeno, como Caturra Vermelho e Vila Sarchi de Coffea arabica, mostraram-se, também, pouco produtivas. Destacou-se apenas a progênje C 1669, rústica. Das.combinaçōes do Hibrido de Timor com outros cultivares de $C$. arabica com resistência a $H$. vastatrix, apenas a progênie $C 1698$ se revelou melhor. As progênies $F_{2}$ derivadas de cruzamentos do cultivar $S .795$ portador do fator $S_{H} 3$ de resistência corn Mundo Novo, deram produçōes bastante razoáveis. Notou-se, de modo geral, acentuada variabilidade na produção das progênies, o que é indicado pelos elevados valores dos coeficientes de variação obtidos nos trés experimentos. Os dados desses experimentos mostraram a dificuldade de aproveitamento das progênies e dos derivados do Híbrido de Timor analisados. Tratando-se, no entanto, de material de elevado grau de resistência às raças de $H$. vastatrix, novas hibridaçōes deverão ser sintetizadas, com cultivares comerciais, a fim de se conseguirem linhagens resistentes, vigorosas e mais produtivas.
\end{abstract}

Termos de indexação: Hibrido de Timor, ferrugem do cafeeiro, resisténcia a Hemileia vastatrix.

(1) Trabalho realizado com auxfito parcial do Convénio SAA-IAC Instituto Brasileiro do Café. Recebido para publicação em 13 de dezembro de 1988 e aceito em 4 de maio de 1989.

(2) Seção de Genética, Instituto Agronômico (IAC), Caixa Postal 28, 13001 Campinas, SP.

(3) Com bolsa de pesquisa do CNPq. 


\section{INTRODUÇÃO}

A partir de 1956, iniciou-se um profícuo intercâmbio de informações sobre a resistência genética do cafeeiro ao agente da ferrugem-das-folhas (Hemileia vastatrix) entre o Instituto Agronômico de Campinas (IAC) e o Centro de Investigaçāo das Ferrugens do Cafeeiro (CIFC) de Portugal. Numeroso material foi recebido em Campinas, para ser testado com relação a sua adaptação e produtividade. Do recebido em 1971, destacaram-se várias seleçōes do café conhecido por Híbrido de Timor e, também, descendentes de hibridações realizadas em Portugal, entre esse café e outras fontes de resistência ao agente dà ferrugem. O Hibrido de Timor é resultante de um cruzamento natural entre Coffea arabica e C. canephora; suas seleções, principalmente as de prefixos CIFC 832/1 e $832 / 2$, apresentam resistência às raças conhecidas de $H$. vastatrix e se cruzam facilmente com cultivares de $C$. arabica. O Híbrido de Timor vem sendo estudado em numerosas regiōes cafeeiras (BETTENCOURT, 1973). A produção dessas progênies e de outras provenientes de vários cruzamentos com resistência genética ao patógeno, nas condições de Campinas, é analisada no presente trabalho.

\section{MATERIAL E MÉTODOS}

Três ensaios de progênies, EP 124, EP 127 e EP 128 foram instalados no Centro Experimental do Instituto Agronômico em Campinas, em 1972, contendo progênies de polinização livre do Hibrido de Timor (CIFC 832/1 e 832/2) e derivadas de hibridaçōes deste com outrós cultivares de Coffea arabica, como Caturra Vermelho (Ct V), Vila Sarchi (VS), Wush-Wush (WW), Mokka (Mo), $\mathrm{S}_{4-}$ -Agaro (S4A), Blue Mountain (BM), Dilla \& Alghe (DA), Vila Lobos (VL), N39, K7, KP423, F840 e H66 e outros híbridos envolvendo os cultivares Mundo Novo (MN), Catuai Vermeltho (Ctu V), Geisha (Gei), BA10, KP263, KP532, S795, S $12-\mathrm{Kaffa}$, S333, Coorg, Gera, Matari, Bourbon Vermelho (BV) e Dewbi. Esse material, em geração $F_{2}$ a $F_{4}$, é proveniente de sementes recebidas, na maioria, do CIFC. No experimento EP 124, foram testadas 68 progênies, sendo 14 do Hibrido de Timor, 18 de seus cruzamentos com Caturra Vermelho, duas com Vila Sarchi, $21 \mathrm{com}$ outras fontes de resistência, 13 de cruzamentos entre outras fontes de resistência e testemunhas, representadas pelos cultivares Acaiá e Catuai Vermelho de $C$. arabica. As progênies de maior interesse foram plantadas em maior número, como se fossem tratamentos diferentes, totalizando 144 tratamentos. $O$ experimento foi estabelecido com delineamento látice $12 \times 12$, três repetiçōes, parcelas de três covas e uma planta por cova. No EP 127, analisaram-se 9 progênies dife- 
rentes, plantadas em blocos ao acaso, 15 repetiçōes, parcela de uma única cova, uma planta por cova, sendo cinco do Híbrido de Timor, duas derivadas do cruzamento de Mundo Novo com S 795, uma de Catuai com Dilla \& Alghe, uma do retrocruzamento do híbrido (Caturra Vermelho com $\mathrm{H}$. de Timor) com Bourbon Vermelho. Também neste experimento algumas progênies foram plantadas com maior número de cafeeiros, dando um total de 16 tratamentos e duas testemunhas (Acaiá e Catuaí Amarelo). O EP 128, com 15 progênies e uma testemunha (Catuaí Amarelo), foi plantado com delineamento inteiramente casualizado, número diferente de repetições por tratamento, parcela de uma cova e uma planta por cova. Analisaram-se as seguintes progênies derivadas do cruzamento do Hibrido de Timor: duas com Vila Sarchi; três com Caturra Vermelho; três com Vila Lobos e uma com $K 7$, além de uma progênie derivada da hibridação de Mundo Novo com S 795, outra de cada um dos altivares Coorg, Dewbi, Matari e Gera e uma derivada do retrocruzamento do híbrido (Catuma Vermelho com H. de Timor) com Bourbon Vermelho.

Os cultivares Geisha, Wush-Wush, Dilla \& Alghe, Gera e Dewbi são portadores do fator genético $S_{H} 1$ de resistência a várias raças de $H$. vastatrix; N39, $\mathrm{KP} 423, \mathrm{~F} 840, \mathrm{~K} 7, \mathrm{H66}$, S795, BA10 e Coorg, do fator $\mathrm{S}_{\mathrm{H} 2}$; $\mathrm{S} 795$ e BA10, do fator $\mathrm{S}_{\mathrm{H} 3}$; Wush-Wush e $\mathrm{S}_{4}$-Agaro, de $\mathrm{S}_{\mathrm{H}} 4$, e os outros cultivares de $C$. arabica como Mundo Novo, Catuaí, Caturra, Vila Sarchi, Vila Lobos, Mokka e Bourbon VermeIho, do fator $\mathrm{S}_{\mathrm{H} 5}$ (BETTENCOURT \& RODRIGUES JR., 1988). Não se usaram tratamentos fitossanitários para combate ao agente da ferrugem nem para as testemunhas suscetiveis.

Para apresentação dos dados de produção do EP 124, reuniram-se no quadro 1 as progênies do Híbrido de Timor, no quadro 2, as derivadas de cruzamentos desse híbrido com cultivares de porte pequeno, como Caturra Vermelho e Vila Sarchi; no quadro 3, as derivadas de cruzamentos do Híbrido de Timor com cultivares portadores de outros fatores de resistência e, no quadro 4 , os demais híbridos entre cafeeiros com fatores distintos de resistência nāo-específica, porém não aparentados com o Hibrido de Timor. No EP 127, foram feitos apenas alguns agrupamentos e, no EP 128, nenhum agrupamento.

Nos três experimentos sāo indicados os prefixos que as introduções estudadas receberam no Instituto Agronômico e no CIFC, a fim de serem mais bem identificadas. Efetuou-se a colheita individual dos cafeeiros por oito anos consecutivos, entre 1974 e 1981, a qual foi expressa em quilograma de frutos maduros. O experimento EP 124, embora tenha sido instalado com o delineamento em látice, foi analisado em blocos ao acaso. Nos experimentos EP $127 \mathrm{e}$ EP 128, realizaram-se as comparaçōes das médias de produção pelo teste de Duncan a $5 \%$. No EP 124, em vista da grande variabilidade notada na produçāo, calculou-se o intervalo de confiança para cada tratamento, usando-se o teste t a $5 \%$, e efetuaram-se comparações entre os valores médios obtidos. O coeficiente de variação para cada progênie dos três experimentos foi calculado, a fim de indicar o grau de variabilidade das progênies. 


\section{RESULTADOS}

Os resultados referentes à produção das progênies do experimento EP 124 acham-se nos quadros 1 a 4 . A análise estatística indicou diferençaș significativas ao nivel de $1 \%$ pelo teste $F\left(F=5,43^{* \star}\right)$. O coeficiente de variação do experimento foi de $43,7 \%$. No quadro 1 , reuniram-se os dados sobre a produção apenas do grupo de progênies do Hibrido de Timor.

As testemunhas Acaiá e Catuai Vermelho, com produção total média de 14,9 e $17,2 \mathrm{~kg}$, mostraram-se mais produtivas do que a maioria das progênies do Híbrido do Timor, e as produçōes deste cultivar revelaram-se muito variáveis, como atestam os altos valores dos coeficientes de variação. Algumas progênies do Híbrido de Timor, de prefixos C 1737, C 1738 e C 1699, deram produçōes médias pouco melhores: $11,7,11,6$ e 10,4kg respectivamente. A amplitude de variação das plantas individuais mostrou que as progênies C 1742, C 1700, C 1738 e C 1699 encerram plantas com produçōes mais elevadas, 24,9, 22,4, 20,6 e $19,9 \mathrm{~kg}$ respectivamente. As diferenças entre as progênies podem ser analisadas através do intervalo de confiança.

O quadro 2 refere-se ao grupo de progênies $F_{2}$ a $F_{4}$ dos cruzamentos do Hibrido de Timor com os cultivares de porte pequeno Caturra Vermelho e Vila Sarchi (BETTENCOURT \& LOPES, 1976; BETTENCOURT et al., 1979; CARVALHO et al., 1984).

A produção média das progênies foi bem menor em relação à do Catuai Vermelho, $17,2 \mathrm{~kg}$. Destacou-se a C 1669 , com $11,3 \mathrm{~kg}$, produção média que não diferiu da testemunha, utilizando o intervalo de confiança para comparação. Além disso, apresentou planta com produção máxima de $25,1 \mathrm{~kg}$, semelhante à do Catuaí, $28,2 \mathrm{~kg}$. O coeficiente de variação dessa progênie foi de $35,6 \%$, enquanto o do Catuaí foi de $12,3 \%$. Os dados dos coeficientes de variação das progênies do quadro 2 revelaram-se também muito elevados, o que pode ser devido à segregaçāo ocorrida ou à falta de adaptação das plantas às condiçōes de ambiente.

No quadro 3 encontram-se os resultados de produção do grupo de progênies $F_{2}$ a $F_{4}$ de cruzamentos entre o Híbrido de Timor e cafeeiros com outros fatores para resistênçia específica a $H$. vastatrix (BETTENCOURT, 1981).

As médias de produção total das progênies dos vários cruzamentos foram todas inferiores às das testemunhas Acaiá, 14,9, e Catuai Vermelho, 17,2kg, com exceção da C 1698 (N39 x 832/2), que apreșentou produção média de $11,8 \mathrm{~kg}$, pouco maior, semelhante à do Acaiá, a basear-se nos intervalos de confiança. Seu coeficiente de variação, de $32,2 \%$, não foi tão elevado como o das demais progênies. Com relação às produçōes individuais, as progênies $C 1681$, C 1690, C 1689 e C 1698, apresentaram plantas com produçōes máximas de $22,5,21,9,19,9$ e $17,0 \mathrm{~kg}$ respectivamente. 
QUADRO 1. Produção média, por planta, de café cereja, no perfodo 1974-81, amplitude de variação e coeficiente de variação da produção das plantas individuais das progênies do café Híbrido de Timor, no Experimento 124, no Centro Experimental de Campinas

\begin{tabular}{|c|c|c|c|c|c|c|}
\hline \multirow{2}{*}{$\begin{array}{l}\text { Identificação } \\
\text { das progênies(1) } \\
\text { IAC }\end{array}$} & \multirow{2}{*}{ CIFC } & \multirow{2}{*}{$\begin{array}{c}\text { Número } \\
\text { de } \\
\text { plantas }\end{array}$} & \multicolumn{4}{|c|}{ Produção } \\
\hline & & & Média & $P(2)$ & Amplitude de variaçāo & $\operatorname{CV}(3)$ \\
\hline \multicolumn{3}{|l|}{ Hibrido de Timor } & $\mathrm{kg}$ & $\mathrm{kg}$ & $\mathrm{kg}$ & $\%$ \\
\hline C 1737 & 4192 & 9 & 11,7 & 16,91 & $0,9-19,8$ & 58,2 \\
\hline C 1738 & 4192 & 27 & 11,6 & 3,44 & $0,1-20,6$ & 39,1 \\
\hline C 1699 & 4121 & 27 & 10,4 & 1,62 & $0,1-19,9$ & 20,1 \\
\hline C 1744 & $4194 \mathrm{C}$ & 18 & 9,5 & 4,49 & $0,2-19,4$ & 45,6 \\
\hline C 1734 & 4191 & 9 & 9,2 & 11,40 & $0,3-17,4$ & 50,0 \\
\hline C 1742 & $4194 A$ & 45 & 7,6 & 2,78 & $0,4-24,9$ & 66,1 \\
\hline C 1700 & 4123 & 54 & 6,9 & 1,79 & $0,5-22,4$ & 52,3 \\
\hline$C 1678$ & $4197(832 / 1)$ & 45 & 5,8 & 1,43 & $0,1-15,4$ & 44,6 \\
\hline$C, 1745$ & 4195 & 9 & 5,1 & 4,39 & $2,5-7,4$ & 34,7 \\
\hline C 1701 & 4125 & 36 & 4,7 & 2,05 & $0,1-16,5$ & 67,3 \\
\hline C 1702 & 4208 & 18 & 4,4 & 2,36 & $0,5-18,0$ & 51,1 \\
\hline C 1677 & $4107(832 / 1)$ & 72 & 4,1 & 0,86 & $0,1-15,6$ & 50,2 \\
\hline C 1746 & 4196 & 9 & 3,8 & 6,23 & $0,8-13,9$ & 66,1 \\
\hline C 1726 & 4184 & 18 & 1,7 & 1,23 & $0,2-4,8$ & 68,8 \\
\hline \multicolumn{7}{|l|}{ Testemunhas } \\
\hline \multirow{2}{*}{\multicolumn{2}{|c|}{$\begin{array}{l}\text { CP 474-7 (Acaia) } \\
\text { LCH 2077-2-5-81-(Catuaí Vermelho) }\end{array}$}} & 9 & 14,9 & 0,72 & $12,7-16,7$ & 2,1 \\
\hline & & 9 & 17,2 & 5,27 & $12,9-28,2$ & 12,3 \\
\hline
\end{tabular}

(1) IAC = Instituto Agronómico de Campinas; CIFC = Centro de Investigaçâo das Ferrugens do Cafeeiro.

(2) $\mathrm{P}=\mathrm{t} 5 \% \times \mathrm{s}_{\overline{\mathrm{m}}}$, sendo $\mathrm{s}_{\overline{\mathrm{m}}}=$ erro padrão da média; intervalo de confiança $=\overline{\mathrm{m}} \pm \mathrm{P}$ (utilizado para comparaçōes estatísticas).

(3) $\mathrm{CV}=$ coeficiente de variação das progénies.

Acha-se no quadro 4 o grupo de progênies de vários hibridos entre cafeeiros portadores de diferentes fatores de resistência.

Os dois hibridos sintetizados em Campinas, $\mathrm{CH} 8110$ e $\mathrm{CH} 8228$, segregando para os fatores $S_{H} 1, S_{H} 2$ e $S_{H} 3$ de resistência respectivamente (BETTENCOURT \& CARVALHO, 1968), tiveram produçōes médias de 15,8 e 15,4kg, que não diferiram estatisticamente das testemunhas Acaiá $(14,9 \mathrm{~kg})$ e Catuai VermeIho $(17,2 \mathrm{~kg})$. $O$ mesmo ocorreu com a progênie $C 1659$, com $11,3 \mathrm{~kg}$, derivada do cruzamento de Caturra com $S$ 795, portadora do fator $S_{H} 3$ de resistência. As produções das plantas individuais mais elevadas foram observadas. nos híbridos CH $8228(25,7 \mathrm{~kg})$ e CH $8110(25,1 \mathrm{~kg})$ e nas progênies C 1694, C 1659 e C 1660, com 19,3, 18,8 e 18,2kg. respectivamente. 


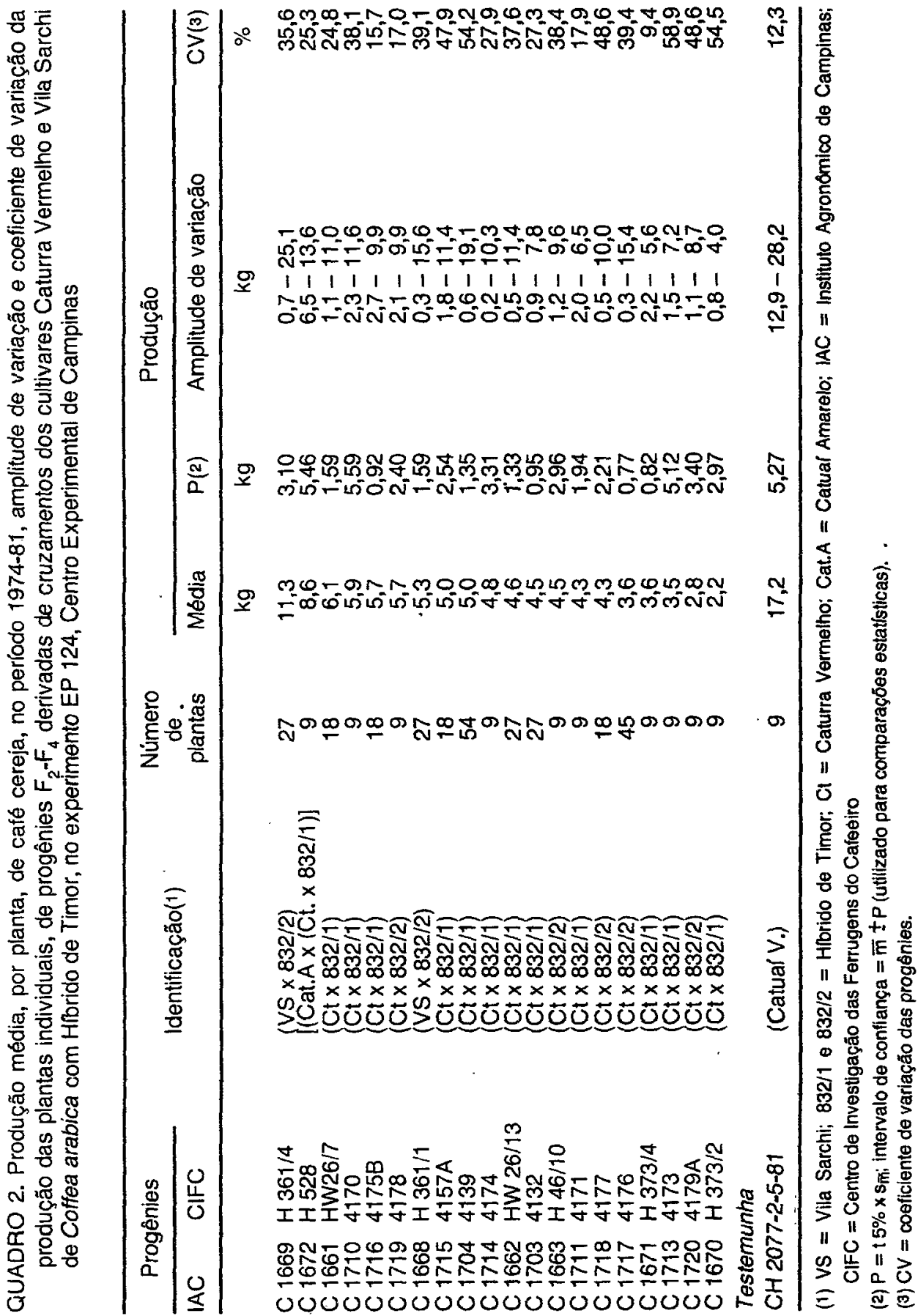




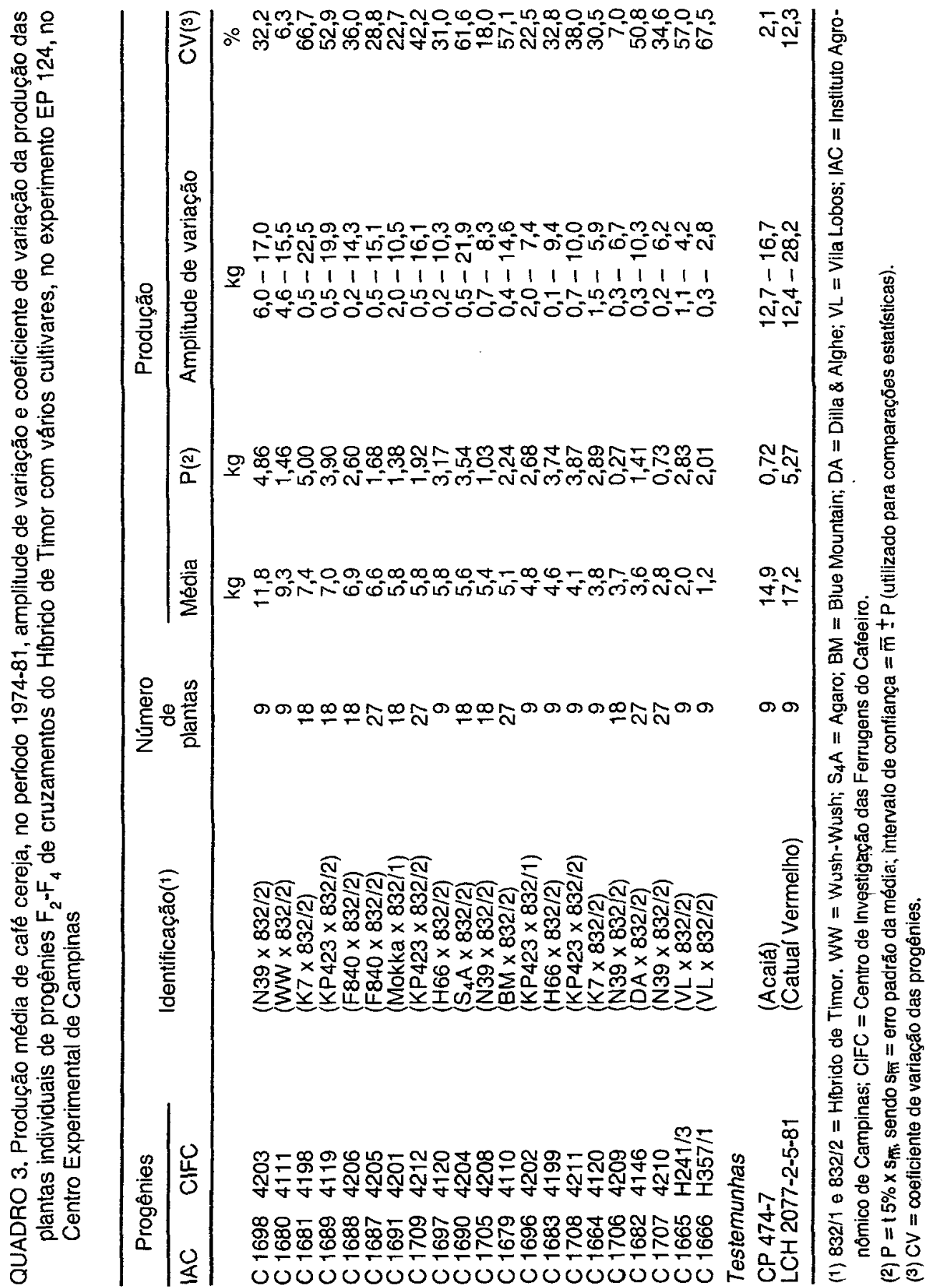




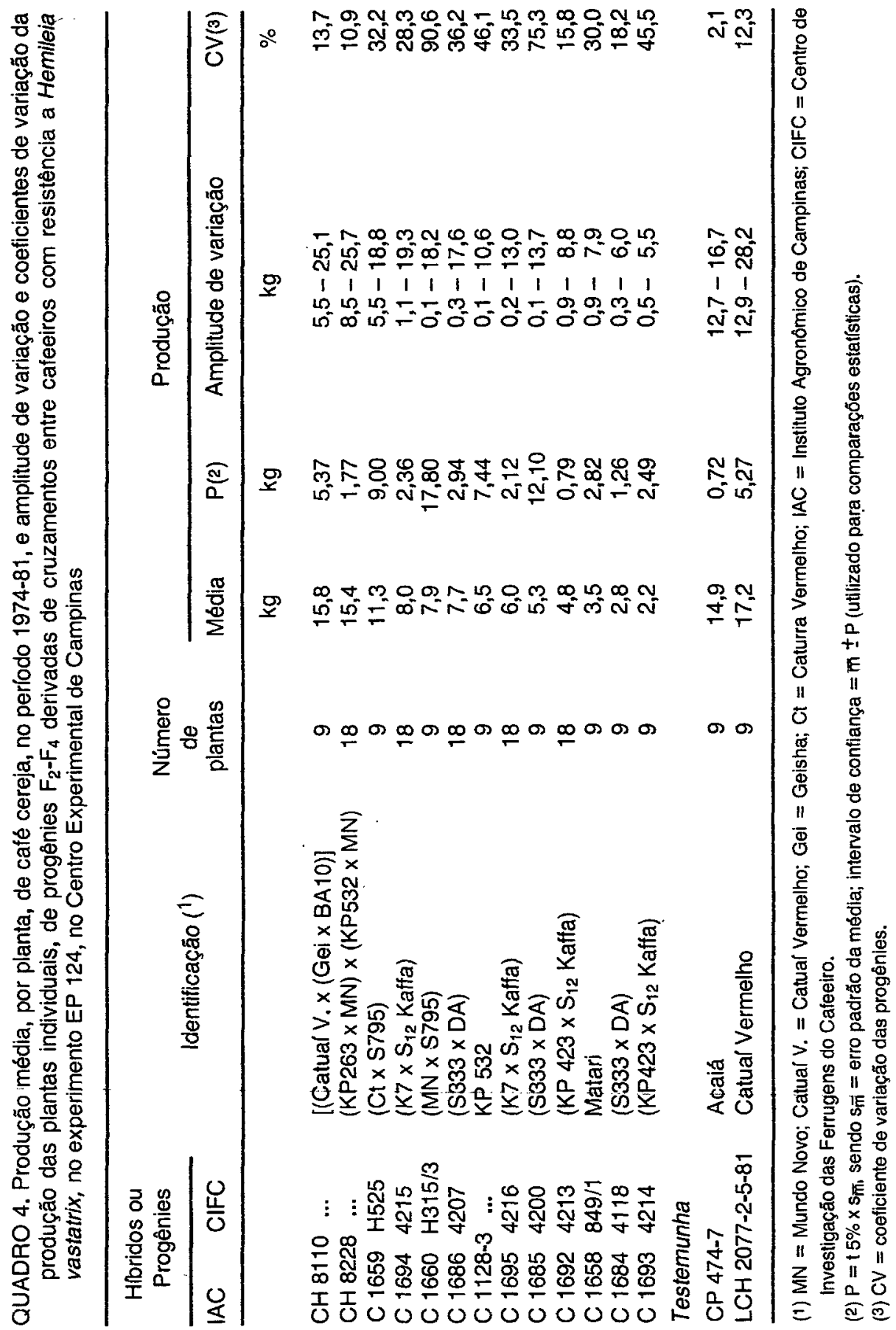




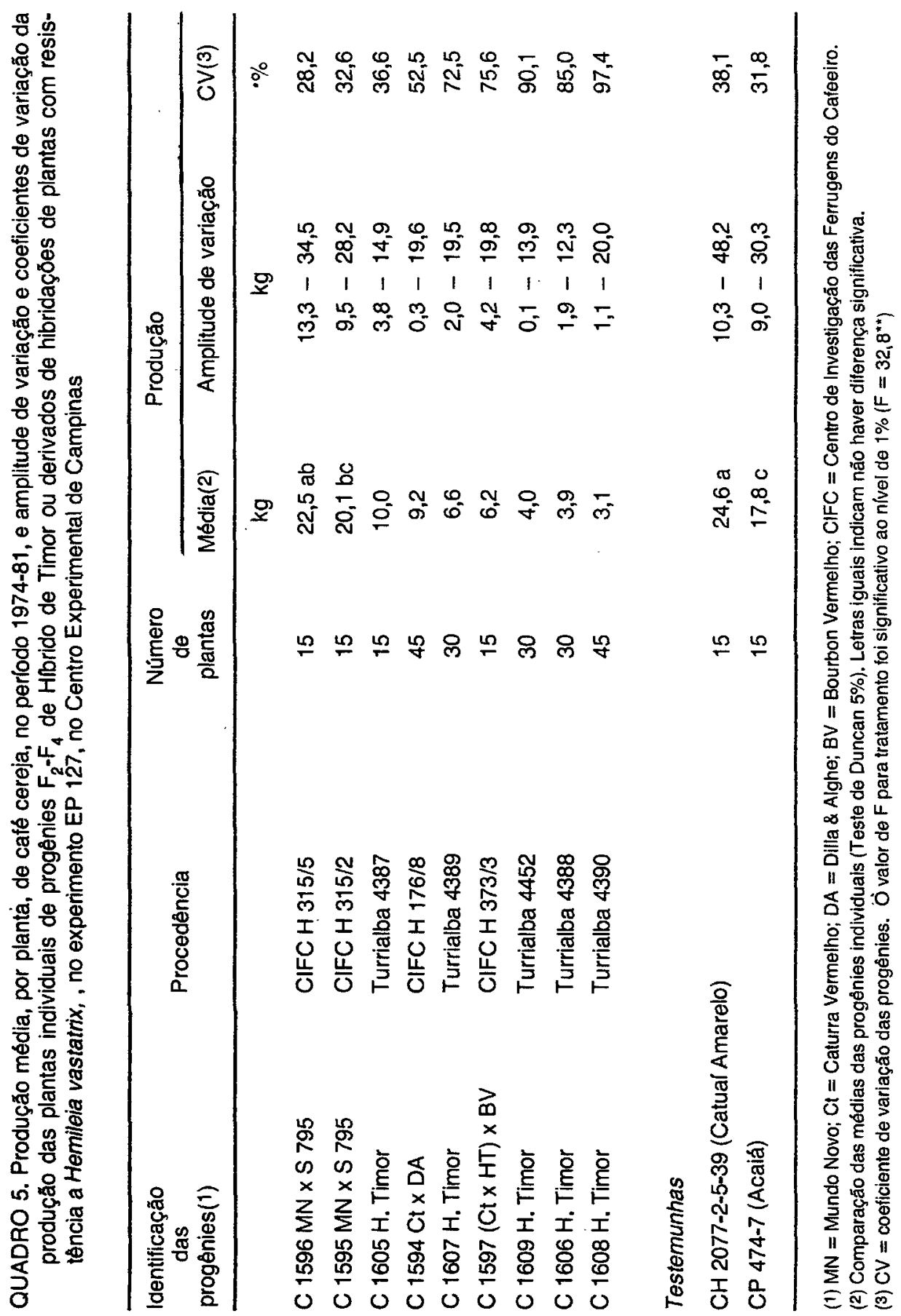




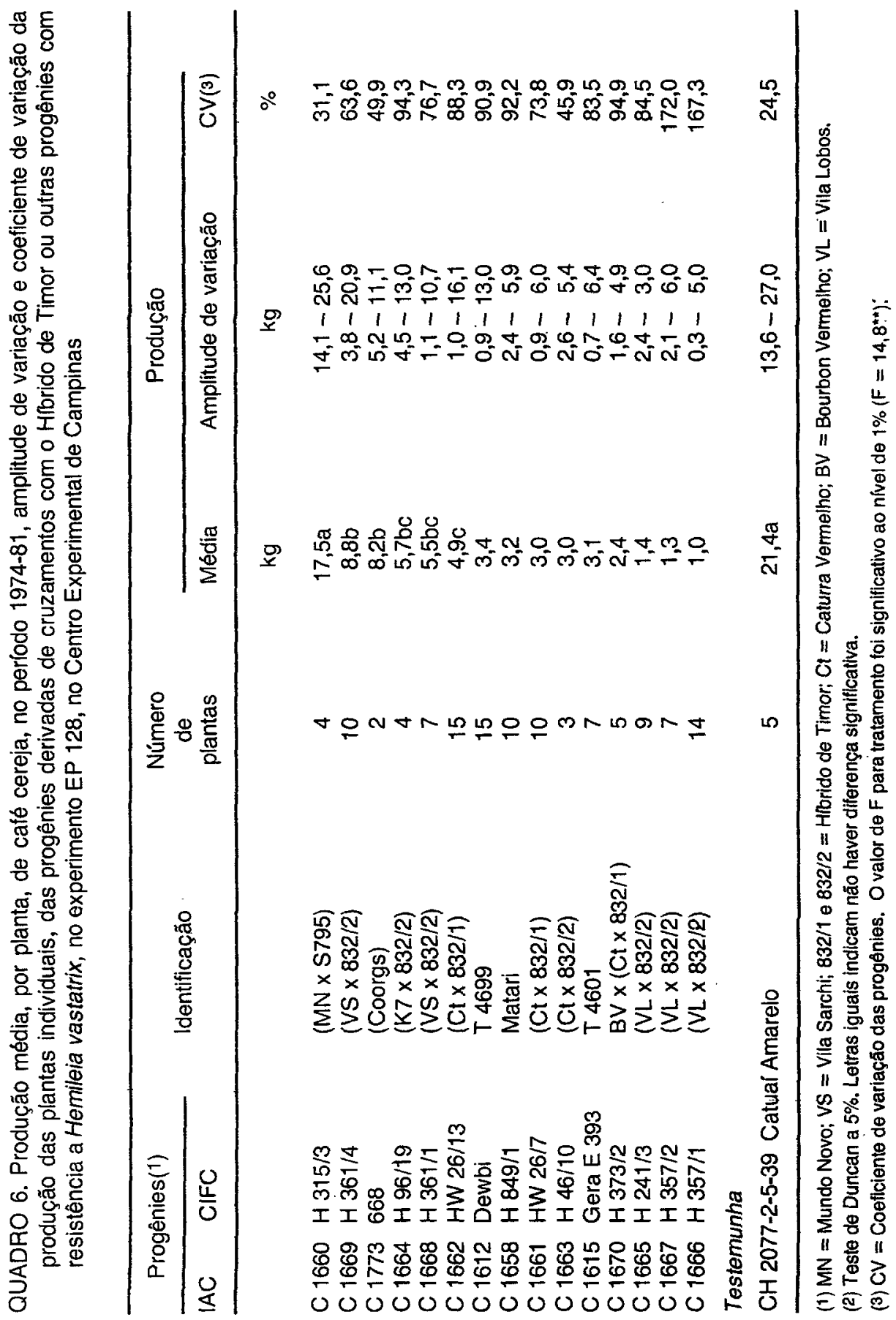


Os dados obtidos referentes ao experimento EP 127 encontram-se no quadro 5. Foram constatadas diferenças altamente significativas entre os tratamentos pelo teste $F\left(F=32,8^{\star \star}\right)$. O coeficiente de variação do experimento foi muito elevado, $51,9 \%$. Verificou-se, pelo teste de Duncan ao nivel de $5 \%$, que a produção da progênie $C 1596 \mathrm{com} 22,5 \mathrm{~kg}$ foiestatisticamente semeIhante à da testemunha Catuai Amarelo, com 24,6kg, e a progênie C 1595,com $20,1 \mathrm{~kg}$, teve produçāo igual à do Acaiá, com 17,8kg. Essas duas progênies, $C$ 1596 e C 1595, que não diferiram entre si quanto à produção, possivelmente sejam portadoras do fator $S_{H} 3$, o qual ocorre no cultivar $S 795$, desenvolvido na Índia (NARASIMHASWAMY, 1960) e usado nas hibridações. Verificaram-se produções individuais mais elevadas nas progênies C 1596 (34,5kg) e C 1595 $(28,2 \mathrm{~kg})$. Verificaram-se, também, valores muito elevados do coeficiente de variação na maioria das progênies analisadas.

Os dados do quadro 6 referem-se ao experimento EP 128 ( $F=14,8$ e CV do experimento $=72,9 \%$ ). As progênies derivadas principalmente de hibridaçōes com o Híbrido de Timor revelaram-se pouco produtivas, com exceção da C 1660 , com $17,5 \mathrm{~kg}$, resultante da hibridação do cultivar Mundo Novo com S795, cuja produçāo não diferiu estatisticamente do Catuai Amarelo $(21,4 \mathrm{~kg})$. A progênie C 1669 , com $8,8 \mathrm{~kg}$, teve produção média inferior, estatisticamente, à da testemunha, embora tenha apresentado uma planta com produçāo de $20,9 \mathrm{~kg}$, semelhante à da melhor planta do Catuai Amarelo $(27,0 \mathrm{~kg})$. Os coeficientes de variação das progênies, em geral, foram muito elevados.

\section{DISCUSSÃO E CONCLUSÕES}

O híbrido de Timor é valioso para os programas de melhoramento visando à resistência ao agente da ferrugem. Além de a introdução CIFC $832 / 1$ se manter resistente, até o momento, a todas as raças do patógeno conhecidas, é tetraplóide e se cruza facilmente com os cultivares de C. arabica, favorecendo a transferência da sua resistência (RIJO, 1974). É, no entanto, pouco produtivo e de pouca ruisticidade, em nossas condiçōes. Essa baixa capacidade de produção talvez seja conseqüência de ter-se originado de cruzamento espontâneo entre cafeeiros não selecionados pela produção, das espécies $C$. arabica e $C$. canephora. As seleções do Híbrido de Timor assemelham-se a cafeeiros do cultivar Arábica de $C$. arabica, o que faz supor que esse cultivar tenha entrado na hibridação original. Sabe-se que o Arábica apresenta pouca rusticidade e baixa capacidade de produção, caracteristicas que devem ter sido transferidas ao Hibrido de Timor.

Seleçōes derivadas das melhores plantas das progênies mais produtivas do Hibrido de Timor, destes experimentos, analisadas em outros, em Campinas e em outras localidades paulistas (dados não publicados) não se revelaram produtivas. 
Isso faz supor que essa melhor performance nos experimentos aqui analisados tenha sido resultado de influência do meio ambiente e que a falta de rusticidade e baixa produção sejam características do Híbrido de Timor.

Os descendentes dos cruzamentos do Híbrido de Timor com cafeeiros de porte pequeno, como Caturra Vermelho e Vila Sarchi, embora resistentes ao agente da ferrugem, revelaram-se, também, nas condições de Campinas, pouco produtivos, com exceção da progênie C 1669. Esta, mesmo assim, apresentou produção menor do que a do Catuai Amarelo e Catuai Vermelho, sem tratamento fitossanitário contra a ferrugem. Ao contrário do que ocorreu em Campinas, algumas progênies derivadas de hibridaçōes de Caturra com o Hibrido de Timor vêm-se desenvolvendo bem e dando boas produçōes em outras regiōes cafeeiras do Brasil, tal como em Minas Gerais (PEREIRA et al., 1987) e em outros países cafeicultores, como em Quênia (NEW CBD..., 1985), Colômbia (MORENO RUIZ \& CASTILHO ZAPATA, 1984), Índia e EI Salvador (BETTENCOURT \& RODRIGUES JR., 1988).

Cultivares como Dilla \& Alghe, K7, KP 423, H 66, F 840, N39, Agaro, Vila Lobos, Blue Mountain e Mokka, com fatores que conferem resistência especifica a $\mathrm{H}$. vastatrix, também não deram combinaçoēs produtivas, quando cruzados com o Hibrido de Timor. Os hibridos entre Mundo Novo e S 795, portadores do fatợ de resistência $S_{H} 3$, fazem exceção e parecem mais promissores, porquanto os isolados da ferrugem com o fator $v_{3}$ de virulência nāo se têm mostrado agressivos em nossas condiçōes (ESKES, 1983).

De modo geral, nos três experimentos, verificou-se alta variabilidade na produção, com valores de coeficientes de variação das progênies muito elevados, indicando pouca capacidade de adaptação do material a nossas condiçōes e provável segregação genética para fatores que influem sobre a produtividade.

Como o Híbrido de Timor constitui valiosa fonte de genes para resistência às raças de $H$. vastatrix, novas combinações híbridas estão sendo sintetizadas e testadas, para conseguir seleções que aliem rusticidade, produção, qualidade de bebida e resistência ao agente da ferrugem, além de outras caracteristicas de interesse econômico.

\section{SUMMARY}

COFFEE BREEDING. XLI: YIELD OF 'HIBBRIDO DE TIMOR' PROGENIES, ITS DERIVATIVES AND OTHER SOURCES OF RESISTANCE TO HEMILEIA VASTATRIX

'Hibrido de Timor' coffee is probably derived from a natural cross between Coffea arabica and $C$. canephora. Selections carried out at the "Centro de Investigação das Ferrugens do Cafeeiro", Portugal, resulted in the isolation of tetraploid self-compatible coffee plants, like CIFC 832/1 and 
832/2, with high resistance to coffee leaf rust and which hybridize easily with C. arabica cultivars. Selections of 'Hibrido de Timor' and $F_{2}-F_{4}$ populations derived from crosses between 'Hibrido de Timor' and other sources of resistance to coffee leaf rust and also from crosses among plants of these other sources of resistance, were planted in 1972, in Campinas, State of São Paulo, Brazil, on three field trials: Catuai Vermelho, Catuai Amarelo and Acaiá cultivars of $C$. arabica were used as control. No chemicals were used to control leaf rust. Yield of ripe berries was determined for individual coffee trees during eight consecutive years (1974-81). Except for the progenies C 1737, C 1738 and C 1699, all other 'Hibrido de Timor' progenies showed very low yields. Yields of descendents from crosses with short size Caturra Vermelho and Vila Sarchi cultivars of $C$. arabica, were also low, except for C 1669. Progenies derived from crosses of 'Hibrido de.Timor' with cultivars carrying other known genes for resistance to coffee leaf rust, gave also poor yields, except for the progeny C 1698 (N39 x 'Hibrido de Timor') with moderate yield. Crosses of the $S 795$ cultivar with Mundo Novo were promising in relation to yield and leaf rust resistance. High yield variability was noted for almost all progenies with high coefficients of variation, indicating low plant adaptation. Despite the general low yielding capacity of 'Hibrido de Timor' and its derivatives, new hybrids are being synthesized in Campinas, aiming at the development of more adapted, high yielding and rust resistant progenies.

Index terms: Hibrido de Timor coffee, coffee leąf rust, resistance to Hemileia vastatrix.

\section{REFERÊNCIAS BIBLIOGRÁFICAS}

BETTENCOURT, A.J. Consideraçōes sobre o Hibrido de Tirnor. Campinas, Instituto Agronômico, 1973. 20p. (Circular 23)

- Melhoramento do cafeeiro: transferência de fatores de resistência a Hemileia vastatrix para os principais cultivares de Coffea arabica. Lisboa, Centro de Investigação das Ferrugens do Cafeeiro, 1981. 93p.

\& CARVALHO, A. Melhoramento do cafeeiro visando resistência à ferrugem. Bragantia, Campinas, 27:35-68, 1968.

\& LOPES, J. Transferência de fatores de resistência a Hemileia vastatrix do HFbrido de Timor para o cultivar Caturra Vermelho de Coffea arabica. In: CONGRESSO BRASILEIRO DE PESQUISAS CAFEEIRAS, 4., Caxambu, 1976. Anais. p.287-291.

;- \& GODINHO, I.L. Transferência de fatores de resistência a Hemileia vastatrix do Hbridó de Timor para o cultivar Caturra Vermelho de Coffea arabica. Garcia de Orta - Ser. Est. Agron., Lisboa, 6(1-2):11-18, 1979.

\& RODRIGUES JUNIOR, C.T. Principles and practice of coffee breeding for resistance to rust and other diseases. In: CLARKE, R.J. \& MACRAE, R., eds. Coffee: Agronomy. London, Elsevier, 1988. Chap. 6, p.199-234.

CARVALHO, A.; MEDINA FILHO, H.P.; FAZUOLI, L.C. \& COSTA, W.M. Genética de Coffea. XXVI. Hereditariedade do porte reduzido do cultivar Caturra. Bragantia, Campinas, 43(2):443-458. 1984. 
ESKES, A.B. Incomplete resistance to coffee leaf rust (Hemileia vastatrix). Wageningen, Agricultural University, 1983. 140p. Thesis (Doutorado)

MORENO RUIZ, G. \& CASTILHO ZAPATA, J. La variedad Colombia: una variedad de café con resistencia a la roya (Hemileia vastatrix). Caldas, Federación Nacional de Cafeteros de Colombia, Centro Nacional de Investigaciones de Café, 1984. 25p. (Boletin técnico, 9)

NARASIMHASWAMY, R.L. Arabica selection S 795: its origin and performance - a study. Indian Coffee, 24:197-204, 1960.

NEW CBD leaf rust resistant variety launched. Kenya Coffee, Nairobi, 50(587):378-382, 1985.

PEREIRA, A.A.; MENDES, A.N.G.; ZAMBOLIN, L.; VALLE, F.X.R. do \& CHAVES, G.M. Retrospectiva e potencial do germoplasma de Catimor nas principais regiōes cafeeiras do Estado de Minas Gerais. In: CONGRESSO BRASILEIRO DE PESQUISAS CAFEEIRAS, 14., Campinas, 1987. Anais. p.116-118.

RIJO, L. Observações cariológicas no cafeeiro Hibrido de Timor. Portugaliae Acta Biologica, Lisboa, 13:157-168, 1974. 